\title{
A PROPÓSITO DE LA LITERATURA MAPUCHE CONTEMPORÁNEA: DANIELA CATRILEO Y LA POESÍA MAPUCHE URBANA INCIPIENTE DEL SIGLO XXI
}

\author{
IN RELATION TO CONTEMPORARY MAPUCHE LITERATURE: DANIELA \\ CATRILEO AND INCIPIENT MAPUCHE URBAN POETRY OF CENTURY XXI
}

\author{
Fabián A. Bloomfield \\ Facultad de Ciencias Sociales, Universidad de Concepción, Chile. \\ fabianandresbloomfield@gmail.com
}

$\mathrm{D}$ esde finales del siglo XX, en sus últimas décadas, la poesía mapuche ${ }^{1}$ ha sufrido un alza, o mejor dicho aún, un punto de emergencia. Sus obras han provenido desde poetas como Leonel Lienlaf Lienlaf, César Millahueique, Graciela Huinao y Eliana Pulquillanca, todos ellos mapuches desde las periferias rurales y luego movilizados a los centros urbanos desde donde construyeron sus obras literarias.

Actualmente, Daniela Catrileo, mapuche y profesora de filosofía, residente en la ciudad de Santiago de Chile, comprende una de las -jóvenes- poetas más recientes e incipientes ${ }^{2}$ desde aquel pueblo indígena, ge-

\footnotetext{
${ }^{1}$ Actualmente los mapuches corresponden al grupo étnico más numeroso en Chile y Argentina. Sin embargo, su población en Chile es casi 10 veces mayor. (Para mayor información ver los siguientes datos estadísticos: "Instituto Nacional de Estadística y Censos (octubre de 2012). Censo Nacional de Población, Hogares y Viviendas 2010. Tomo 1. Buenos Aires, Argentina." y los "Resultados Censo 2017 del Instituto Nacional de Estadísticas de Chile": https://resultados.censo2017.cl/)

${ }^{2}$ Para el año 2017 y 2018 ha realizado un número no menor de entrevistas, a mi consideración, una de las más importantes realizada el martes 24 de julio de 2018 en el canal televisivo nacional chileno C13 (en línea: http://www.13.cl/c/programas/off-the-record/ capitulos/la-poeta-daniela-catrileo-y-la-reivindicacion-mapuchehttp://www.13.cl/c/ programas/off-the-record/capitulos/la-poeta-daniela-catrileo-y-la-reivindicacion-mapuche. A su vez, ha tenido menciones en distintos medios de importancia resaltando CNN Chile, donde se la considera "una de las revelaciones de la literatura joven" (Disponible en: https://www.cnnchile.com/cultura/daniela-catrileo-dictara-taller-de-literatura-mapuche-gratuito_20180719/).
} 
nerando publicaciones literarias (de baja circulación) desde el año 2007 hasta la actualidad. Sin embargo, es desde el año 2013, con su publicación Río Herido ${ }^{3}$, aquél momento en que empieza a generar su reconocimiento, para luego, el 2016, pasar a cargo de la editorial chileno-italiana Edicola Ediciones, produciendo, hasta el 2018, su tercera reimpresión.

Hoy en día, los mapuches urbanos comprenden uno de los fenómenos migratorios más importantes, asociados a las migraciones indígenas desde las periferias rurales hacia las ciudades en América Latina (Stavenhagen, 1992). La cultura "mapuche-warriache", como se les ha denominado desde la etnología (Aravena, 2001), o simplemente la cultura mapuche urbana, confiere actualmente gran parte de la población mapuche actual. Esta no ha estado anexa de tensiones de identidad en la mantención de su cultura, debido al choque con la cultura dominante que ha estado marcada por la violencia y la discriminación (Aravena, Grandón, Sáez y Zañartu, 2017), siendo aquel contexto desde donde ha emergido el arte literario de Catrileo.

Desde Bourdieu (1989), los escritores y sus prácticas artísticas son el resultado de la relación - en parte- de sus posiciones sociales. La singularidad del creador y el proyecto literario son a su vez un entramado de elementos irreductibles e inseparables. En consecuencia, las propias tensiones identitarias vividas desde los centros urbanos conforman parte innegable del resultado creativo literario. Se conforma una reciente y nuevo tipo de poética emergente desde la ciudad y, mayormente aún, desde el ser mapuche y el ser mujer ${ }^{4}$ desde siempre en la urbe ${ }^{5}$, hecho que no puede ser dejado de lado desde las perspectivas feministas decoloniales, principalmente las de Ochy Curiel (2009, 2014) y Francesca Gargallo (2014).

La obra de Catrileo, Río Herido, ha logrado posicionarse de manera exitosa, más allá de la calidad artística y literaria, en un contexto de cultura de masas, medios y redes propias de una cultura globalizada (Rodríguez y Santana, 2007), donde la inmediatez comunicativa está presente, y se permean en la colectividad y virtualidad discursiva de manera híbrida; donde la internet, su capacidad de circular información, masificación, y el con-

\footnotetext{
${ }^{3}$ Santiago de Chile: Ediciones Libros del Perro Negro.

${ }^{4}$ Es por eso que Mora (2018: 176) señala a Daniela Catrileo como una escritora que ha basado sus escritos “enfatizando en la cuestión de género y otras rupturas”.

${ }^{5}$ Este punto es central, considerando que Catrileo, a diferencia de sus pares poetas, ha sido criada desde la urbanidad.
} 
sumo literario han conformado un orden tal, que la velocidad y el abanico discursivo está sumergido en la contemporaneidad.

La producción y el surgimiento de la(s) obra(s) de este tipo de autores, como Catrileo - siguiendo a Facuse (2010) - , conlleva un vínculo entre la mediatización y la adquisición de sentido con la materialidad de la obra poética por parte de los espectadores, mucho más allá de su juzgamiento estético literario. Además, aquello es mezclado con los comentarios públicos realizados por parte de Catrileo en diversos medios de comunicación ${ }^{6}$ con temas de contingencia nacional, como son las ideas feministas, temáticas de género y educación, tópicos relacionados al contexto de la ley $\mathrm{N}^{\mathrm{o}}$ 18.314 ${ }^{7}$ y la violencia policial hacia el pueblo indígena.

La obra de arte creada por Catrileo ha sido principalmente un producto del artista que conlleva sus propias motivaciones (Bourdieu, 2002, 2010). Por ende, la obra de arte poética comprende un discurso, un entramado poético que dialoga entre lo estético y las subjetividades del emisor (y sus manifiestos). Por tanto, Río Herido como obra de arte se enmarca también como un hecho social (Latour, 1994). Su poética está en la indisoluble separación entre los hechos sociales, el funcionamiento artístico literario y todos sus actores, y cómo estos interactúan de manera discursiva en su poesía (Heinich, 2001).

Este tipo de manifestaciones literarias comprende un riquísimo aporte a la visión del mundo en los estudios literarios y etnológicos, debido a que

${ }^{6}$ Principalmente en el medio digital "El Desconcierto" (https://www.eldesconsierto. cl), con las entrevistas a cargo de Sebastián Flores, publicada en el mismo medio el o5 de diciembre de 2017, donde se toman temas de contingencia nacional como las problemáticas de descolonización indígena, feminismos, temáticas educativas, entre otros. Igualmente existen otras publicaciones cómo la realizada por Naomi Orellana el 04.01.2017 titulada con una cita de Catrileo: "Si luchamos por \#NiUnaMenos, también debemos visibilizar los casos de violencia en Wallmapu" (http://www.eldesconcierto.cl/2017/01/o4/danielacatrileo-poeta-si-luchamos-por-niunamenos-tambien-debemos-visibilizar-los-casos-deviolencia-en-wallmapu/). Esto sin nombrar sus comentarios de Redes de internet privadas, conocidas como Redes Sociales albergadas en sus distintas plataformas. En la misma línea Catrileo ha aparecido en programas televisivos, uno de ellos corresponde al programa Off The Record con el capítulo titulado "La poeta Daniela Catrileo y la reivindicación mapuche", y que fue sacado al aire el día martes 24 de julio de 2018 (en línea: http://www.13. $\mathrm{cl} / \mathrm{c} /$ programas/off-the-record/capitulos/la-poeta-daniela-catrileo-y-la-reivindicacionmapuchehttp://www.13.cl/c/programas/off-the-record/capitulos/la-poeta-daniela-catrileo-y-la-reivindicacion-mapuche)

${ }^{7}$ Conocida en Chile como "ley antiterrorista". 
los mapuches históricamente han privilegiado de manera predominante el desarrollo de la cultura verbal (Carrasco, 1990), pero más aún confiere entender la poética desde la urbanidad y de los puntos urbanos capitales, como son las grandes metrópolis. Por lo demás, no es un hecho desde lo novedoso que la mayor parte de los mapuches asentados en las ciudades no tiene competencias considerables del mapudungún (Lagos 2012), teniendo en cuenta que Río Herido es una obra monolingüe desde el español.

La literatura de Daniela Catrileo confiere una visión política reflejada en su creación, el exilio de la historia en el poema, donde se refleja la memoria y el "río herido" de un pueblo; el río como la vida propia de los sujetos; él y lo que viaja, lo que se mueve desde la memoria, pero herido por la historia y las discursividades dominantes; el fluir de las aguas del río que es el constructor de identidad, que se reconfigura en el espacio de la ciudad, desde los antiguos refugios, los antepasados y la imposibilidad de marcar con letra su historia. Así, el poema Caminé en su funeral de Espigas, hace presente la dualidad propia de ser mapuche en las ciudades: "llevar la cuenta de ancestros / por orden santo / no es recomendable en la juventud.// [...] Sentir el gemido viajero de mi cordura / crecer a la fuerza / hasta dominar la ciudad" (Catrileo, 2018: 53). En aquel contexto, es claro que, desde la poética, "Catrileo se sitúa desde la periferia para reconstruir un tramado vital que aúna aspectos que tienen que ver con lo mapuche, con el feminismo y la ciudad"8 (Legrand, 2017: 7).

Las obras como Río Herido comprenden una forma para entender a los movimientos políticos mapuches, indígenas, e individuos que se apropian en los discursos artísticos que se consumen, y que además permiten el entendimiento de una visión de la contemporaneidad - con la propia percepción desde la urbanidad indígena-, la etnicidad y las relaciones étnicas reflejadas en la poética, donde emergen las imposibilidades a manera de "heridas" antes de las propias "palabras". Mismamente el poema y su discurso se manifiesta como interrogante desde la experiencia social: “¿Cómo escribir un nombre / que nació herido, / antes de ser escrito / antes del origen / de la letra?” (Catrileo, 2018: 15). Así, la literatura es contextual, es un hecho cultural, obedece a la cultura que la crea y que refleja, enmarcada

\footnotetext{
${ }^{8}$ La cursiva es propia
} 
en el discurso de sus autores, en un juego que permite entender la experiencia cultural y artística, en este caso, desde la etnicidad. Es por eso que la importancia de este tipo de obras radica en su contenido literario como discurso ${ }^{9}$, más allá del juicio de su estética poética.

Uno de sus poemas publicados, ya en el mismo libro, recoge las percepciones urbanas de las violencias indígenas localizadas en las periferias rurales. Frente al Enemigo, recoge no sólo la visión propia de los hechos de las violencias contemporáneas, sino que además la transforma en un enunciado que también es político: "Escucho el ritmo de las olas / en su espalda / saltamos un par de veces / para no mojar el espacio / de rocas para no llenar el blanco / de días / que se ahogan por el fuego. // Nunca dijo que corriéramos / para salvarnos. // Nuestro rostro de frente / ante balas. / Nuestros rugidos de frente ante máquinas // Nunca fueron olas" (Catrileo, 2018: 65). Por otro lado, se muestran las heridas de la contemporaneidad, la herida propia de los indígenas que componen la etnia, en un devenir donde se les ha despojado de la sociedad, donde "los muertos no son la historia" (Catrileo, 2018: 22), sino que son los sujetos "sin lengua”, los otros, que viven día a día las prácticas marginalizantes y neocolonizantes de la estructura cultural dominante, los excluidos, a los que Catrileo reclama en la interrogante: “¿De qué sirve / escribirte, si desapareces / en la hoja / en el cauce?” (2018: 22). El poema surge como manifestación al intento del habla, para que los desplazados y sin lengua se unan a la posibilidad y al acontecimiento que es el poema mismo, con un cuestionamiento directo a los espacios urbanos desde la lengua y la memoria (Legrand, 2017), pero más aún confiere al poema como el manifiesto de las subordinaciones que se viven imbricadas donde los contextos de dominación se viven construidos históricamente (Curiel, 2014).

A fin que, Río Herido no se transforma en la actualidad en el estandarte de la estética de la poética mapuche, sino en un discurso literario, político y cultural desde lo decolonial, que surge en el poema como vía de manifestación de parte de Daniela Catrileo: mujer y mapuche urbana, y que son apro-

\footnotetext{
${ }^{9}$ Se sustenta que existe un discurso proveniente desde las mujeres indígenas y cómo estas poseen relaciones de dependencia "frente a los procesos culturales y políticos que han sido resultado del capitalismo, la modernidad occidental, la colonización europea y sus procesos de racionalización" (Curiel, 2014: 236), hechos propios de una sociedad androcéntrica actual y sus efectos (Collins, 1998; Federici, 2013).
} 
piadas por sus consumidores que forman, ambos, parte de las llamadas desplazadas minorías, hechos que son puntos fundamentales y esenciales a considerar en los estudios literarios de la cultura mapuche-warriache, en una ayuda bidireccional con la etnología.

\section{Referencias}

Aravena Reyes, Andrea. 2001. La identidad mapuche - warriache: Procesos migratorios contemporáneos e identidad mapuche urbana. IV Congreso Chileno de Antropología. Colegio de Antropólogos de Chile A. G, Santiago de Chile:, 285-297. Disponible en: https://www.researchgate.net/ publication/288667686_La_identidad_mapuche_-_warriache_Procesos_migratorios_contemporaneos_e_identidad_mapuche_urbana

Aravena Reyes, Andrea. 2007. Identidades indígenas urbanas en el tercer milenio: identidades étnicas, identidades políticas de los mapuchewarriache de Santiago de Chile". Instituto Interamericano de Derechos Humanos, 43-58.

Bourdieu, P. 1989. El campo literario. Prerrequisitos críticos y principios de método. Revista Criterios, 25 (20), 20-42.

Bourdieu, Pierre. 2002. Las reglas del arte. Génesis y estructura del campo literario. Barcelona:Anagrama.

Bourdieu, Pierre. 2010. El sentido social del gusto. Elementos para una sociología de la cultura. Siglo Veintiuno Editores.

Carrasco, I. 1990. Etnoliteratura Mapuche y Literatura Chilena: Relaciones. Actas de la Lengua y literatura Mapuche, (4), 19-27.

Catrileo, Daniela. 2018. Río Herido. Santiago de Chile: Edicola Ediciones.

Collins, P. 1998. La política del pensamiento feminista negro. En: Marysa Navarro y Catherine R. Stimpson ¿Qué son los Estudios de Mujeres?, 253-312. México: FCE.

Curiel, Ochy. 2009. Descolonizando el feminismo: Una perspectiva desde América Latina y el Caribe. Consultado el 25 de julio de 2018, Repositorio Institucional Universidad Nacional de Colombia, en http://www. bdigital.unal.edu.co/39749/

Curiel, Ochy. 2014. Hacia la construcción de un feminismo descolonizado. En Miñoso, Y. E., Correal, D. G., y Muñoz, K. O. (Eds.). Tejiendo de otro 
modo: Feminismo, epistemología y apuestas descoloniales en Abya Yala (pp. 325-334). Popayán: Editorial Universidad del Cauca.

Facuse, Marisol. 2010. Sociología del arte y América Latina: Notas para un encuentro posible. Universum, $\mathrm{N}^{\circ}$ 25: Vol. 1, 74-82.

Federici, S. 2013. La reproducción de la fuerza de trabajo en la economía global y la inacabada revolución feminista. La revolución en punto cero. Trabajo doméstico, reproducción y luchas feministas, red. Silvia Federici. Madrid: Traficantes de Sueños, 153-180.

Gargallo, F. 2014. Feminismos desde Abya Yala: ideas y proposiciones de las mujeres de 607 pueblos en nuestra América. México D. F. Universidad Autónoma de la Ciudad de México.

Heinich, Nathalie. 2001. Lo que el Arte Aporta a la Sociología. México D. F.: Conaculta Ediciones.

Lagos F, Cristián. 2012. El mapudungún en Santiago de Chile: Vitalidad y representaciones sociales en los mapuches urbanos. RLA. Revista de lingüística teórica y aplicada, 50(1), 161-184.

Latour, Bruno. 1994. ¿̇Tienen historia los objetos? El encuentro de Pasteur y de Whitehead en un baño de ácido láctico. Traducción de Javier Echeverría. Isegoría, (12), 92-109.

Legrand, P. 2017. Cuerpo de mujer: La ciudad como constructo en el discurso poético femenino desde los años ochenta a la actualidad en Chile. Ángulo Recto: Revista de estudios sobre la ciudad como espacio plural, 9 (1), 5-15.

Mora Curriao, M. 2018. Muestra de poesía mapuche. Trazas poéticas sobre una cartografía indígena incesante. Anales de la Universidad de Chile, (13), pp. 165-218.

Rodríguez, A, y Santana, Á. 2017. La nueva sociología de las artes: una perspectiva hispanohablante y global. Santiago de Chile: Editorial GEDISA.

Stavenhagen, Rodolfo. 1992. "La situación y los derechos de los pueblos indígenas de América”; Boletín Indigenista; América Indígena, Vol. 52, $\mathrm{N}^{\circ \mathrm{s}}$ 1-2, ene-jun., Instituto Indigenista Interamericano, México, 92-109.

Zañartu Canihuante, Natalia, Aravena Reyes, Andrea, Grandón Fernández, Pamela, Sáez Delgado, Fabiola, y Zañartu Canihuante, Carola. 2017. Identidad étnica, discriminación percibida y procesos afectivos en jóvenes mapuches urbanos. Cultura-hombre-sociedad, 27 (2), 229-250. 